\title{
Load Distribution among the Teeth of Flexspline of Harmonic Drive with Double Circular-arc Tooth Profile
}

\author{
Guihua $\mathrm{Wu}^{1, \mathrm{a}}$, Xiaojiang Peng ${ }^{2, \mathrm{~b}}$ \\ ${ }^{1}$ College of Mechanical and Power Engineering, Chongqing University of Science \& Technology, \\ Chongqing, 401331, China \\ ${ }^{2}$ The State Key Laboratory of Mechanical Transmission, Chongqing University, Chongqing, 400044, \\ China \\ awuguihua1968@126.com, b20140713197@cqu.edu.cn
}

Keywords: Harmonic drive, double circular-arc tooth, load distribution.

\begin{abstract}
Based on the basic theory of harmonic drive, circular spline profile is computed by envelope method when flexspline profile chooses double circular-arc tooth. The load distribution among the teeth of the flexspline has been calculated under different working conditions. When the force intersection angle of the four-acting-force wave Generator decreases, the load distribution will become centralized, and the maximum force acting on the areas of the teeth will also increase.
\end{abstract}

\section{Introduction}

Under the condition of same number of teeth and module, double circular-arc harmonic gear drive has more meshing teeth compared with the involute type harmonic gear drive. That is, the transmission ratio is bigger, the transmission accuracy is higher [1,2]. But after loading, the mutually meshing teeth of harmonic gear drive system produce non-uniform distribution force, and the magnitude of the engagement force will changed by the load torque, tooth shape and structure parameters.

\section{The basic theory of harmonic gear drive}

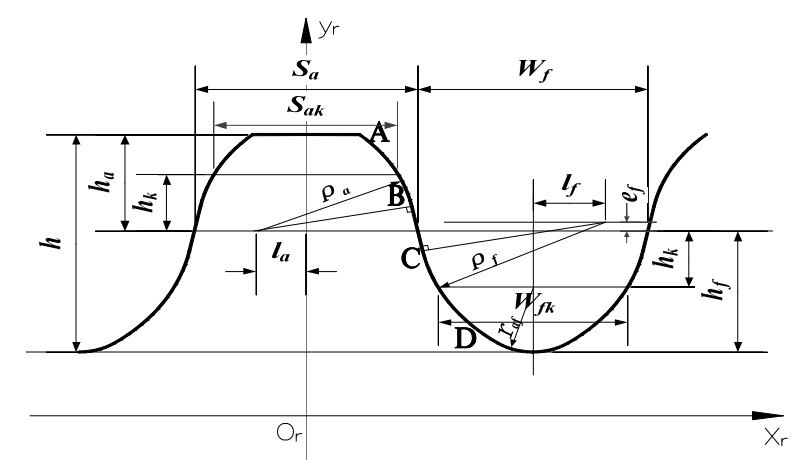

Fig. 1Structure diagram of double circular-arc tooth Profile

Harmonic gear drive is composed of three basic components: flexspline, circular spline, wave generator.

\subsection{Determination of flexspline theoretical tooth profile equation.}

Flexspline coordinate system $\mathrm{C}_{\mathrm{r}}\left(\mathrm{x}_{\mathrm{r}}, y_{\mathrm{r}}\right)$ as shown in Fig. 2.According to the parameters in Fig. 1, the tooth profile equation can be expressed:

Flexspline addendum circular arc $\mathrm{AB}$ equation:

$\left\{\begin{array}{l}x_{r}=\rho_{a} \cos \alpha_{2}-l_{a} \\ y_{r}=\rho_{a} \sin \alpha_{2}+e_{a}+\frac{d}{2}-r_{m}\end{array} \quad\left(\theta_{B} \leq \alpha_{2} \leq \theta_{A}\right)\right.$

Flexspline straight line segment BC equation: 
$\left\{\begin{array}{l}x_{r}=t_{1} \\ y_{r}=k t_{1}+b\end{array}\right.$

Flexspline dedendum circular arc CD equation:

$$
\left\{\begin{array}{l}
x_{r}=\rho_{f} \cos \alpha_{1}+\frac{t}{2}+l_{f} \\
y_{r}=\rho_{f} \sin \alpha_{1}+e_{f}+\frac{d}{2}-r_{m}
\end{array} \quad\left(\theta_{C} \leq \alpha_{1} \leq \theta_{D}\right)\right.
$$

Here, $\mathrm{D}$ is pitch diameter, $r_{m}$ is flexspline midline radius.

Each tooth root position of flexspline after deformation can be determined by using the arc length distribution algorithm [3].

Establish a coordinate system (Fig. 2), write flexspline tooth profile equation and the equation of circular spline profile, flexspline conjugate tooth profile, can be deduced [4].

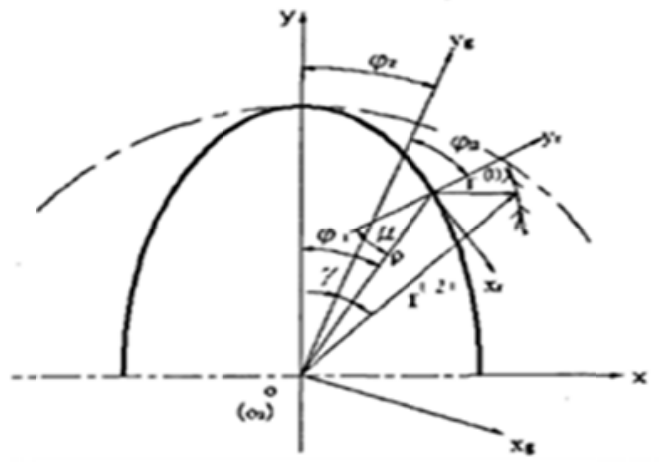

Fig. 2 Coordinate relations to solve the conjugate tooth profile sketch by using the envelope method

Here is the flexspline original curve calculated according to four-roller wave generator model, the function expression of flexspline original curve $\mathrm{C}[5]$ is:

$$
\rho(\varphi)=r_{m}+m \omega_{0}^{*} \frac{\sum_{n=2,4,6 \ldots \ldots} \frac{\cos n \beta \cos n \varphi}{\left(n^{2}-1\right)^{2}}}{\sum_{n=2,4,6 \ldots} \frac{\cos n \beta}{\left(n^{2}-1\right)^{2}}}(4)
$$

Here, $\varphi$ is the flexspline rotation angle of the un-deformed end.

$\beta$ is the force intersection angle between four- roller wave generator.

\subsection{Circular spline tooth profile equation is derived.}

As the flexspline profile equation has been known, circular spline tooth profile equation can be calculated with the flexspline conjugate tooth profile equation. Assuming that wave generator is fixed, flexspline drives, circular spline is driven. The longitudinal axis of 3-D system coincides in the initial position, and the coordinate relationship is shown in Fig. 2.

Presuppose flexspline tooth profile equation $\mathrm{R}$ in a united way:

$\left\{\begin{array}{l}x_{r}=x_{r}\left(\alpha_{i}\right) \\ y_{r}=y_{r}\left(\alpha_{i}\right)\end{array}(5)\right.$

The transformation matrix from the flexspline coordinate system to the circular spline coordinate system:

$M_{g r}=\left[\begin{array}{ccc}\cos \varphi_{12} & \sin \varphi_{12} & \rho \sin \gamma \\ -\sin \varphi_{12} & \cos \varphi_{12} & \rho \cos \gamma \\ 0 & 0 & 1\end{array}\right](6)$

Coordinate transformation formula is:

$\left[\begin{array}{c}x_{g} \\ y_{g} \\ 1\end{array}\right]=M_{g r}\left[\begin{array}{c}x_{r} \\ y_{r} \\ 1\end{array}\right]$ (7)

So the unified expression of circular spline tooth profile $\mathrm{G}$ is:

$\left\{\begin{array}{l}x_{g}=x_{r} \cos \varphi_{12}+y_{r} \sin \varphi_{12}+\rho \sin \gamma \\ y_{g}=-x_{r} \sin \varphi_{12}+y_{r} \cos \varphi_{12}+\rho \cos \gamma\end{array}\right.$ 
According to the theory of envelope, the circular spline tooth profile equation is:

$\left\{\begin{array}{l}x_{g}=x_{g}\left(\alpha_{i}, \varphi\right) \\ y_{g}=y_{g}\left(\alpha_{i}, \varphi\right) \\ \frac{\partial x_{g}}{\partial \alpha_{i}} \cdot \frac{\partial y_{g}}{\partial \varphi}-\frac{\partial x_{g}}{\partial \varphi} \cdot \frac{\partial y_{g}}{\partial \alpha_{i}}=0\end{array}\right.$

Now the original curve $\mathrm{C}$ and flexspline profile equation $\mathrm{R}$ have been calculated, so the conjugate tooth profile $\mathrm{G}$ can be solved according to formula (8).

Where $\varphi_{1}=\varphi+\frac{v(\varphi)}{r_{m}}, \quad v(\varphi)=-\int \omega(\varphi) d \varphi, \quad \varphi_{2}=\frac{Z_{1}}{Z_{2}} \cdot \varphi, \quad \gamma=\varphi_{1}-\varphi_{2}, \quad \mu=\mu(\varphi) \approx \frac{1}{r_{m}} \cdot \frac{d \omega}{d \varphi}, \quad \varphi_{12}=\gamma+\mu, Z_{1}$ is number of flexspline teeth, and $Z_{2}$ is number of circular spline teeth.

\subsection{Instance model.}

Flexspline tooth profile parameters are chosen according to Table 1, the coordinates of each point of circular spline profile are calculated according to the formula (8).

Table1 Flexspline and circular spline basic parameters

\begin{tabular}{ccc}
\hline & Flexspline & Circular spline \\
\hline Module m & 0.5 & 0.5 \\
Number of teeth & $Z_{1}=200$ & $Z_{2}=202$ \\
Radial modification Coefficient & 1 & - \\
Modification coefficient & $X_{1}=0$ & $X_{2}=0$ \\
Module m & 0.5 & 0.5 \\
\hline
\end{tabular}

\section{Calculation and analysis}

\subsection{The influence of load on the engagement force among teeth.}

The following is the comparison of flexispline engagement force distribution under different load conditions. The working condition is chosen as follows: the force intersection angle of the wave generator $\operatorname{roller} \beta=30^{\circ}$, no modification for both flexspline teeth and circular spline teeth $X_{1}=X_{2}=0$, flexspline radial deformation coefficient $\mathrm{w} 0 *=1$.

As shown in Figure 5, the load distribution on flexspline tooth under different loads can be seen:

1) The overall harmonic region of engagement range enlarges as the load increases, but not as linear relation;

2) Load is mainly undertaken by only a few teeth near the long deformation axis, while the load undertaken by the rest teeth is small and uniform distribution.

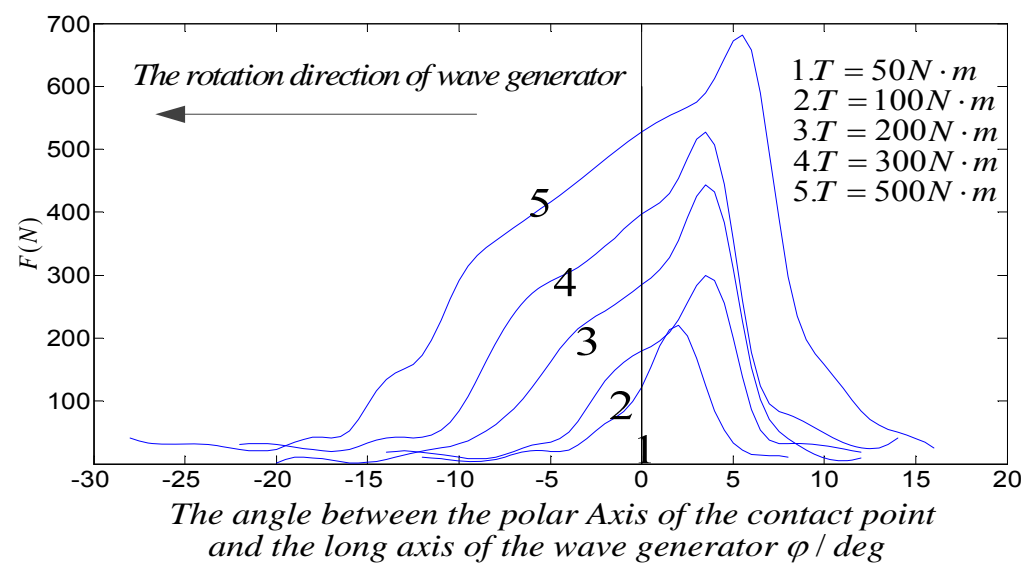

Fig.3 Flexspline engagement force distribution among teeth under different load torques

\subsection{The influence of the wave generator's shape to the load distribution among gear teeth.}

Different shapes of wave generators will directly affect the distribution state of the initial clearance, thus will inevitably impact the distribution of the gear engagement force. Following, flexspline engagement force distribution among teeth under different shapes of wave generator is analyzed. 
The working condition is chosen as follows: no modification for both the flexspline tooth and circular spline tooth $X_{1}=X_{2}=0$, flexspline radial deformation coefficient w0 $*=1$, the load torque $T=$ $300 \mathrm{~N} \cdot \mathrm{m}$. Choose wave generator force intersection angle as $\beta=0,10^{\circ}, 20^{\circ}, 30^{\circ}$ four kinds of conditions to analyze.

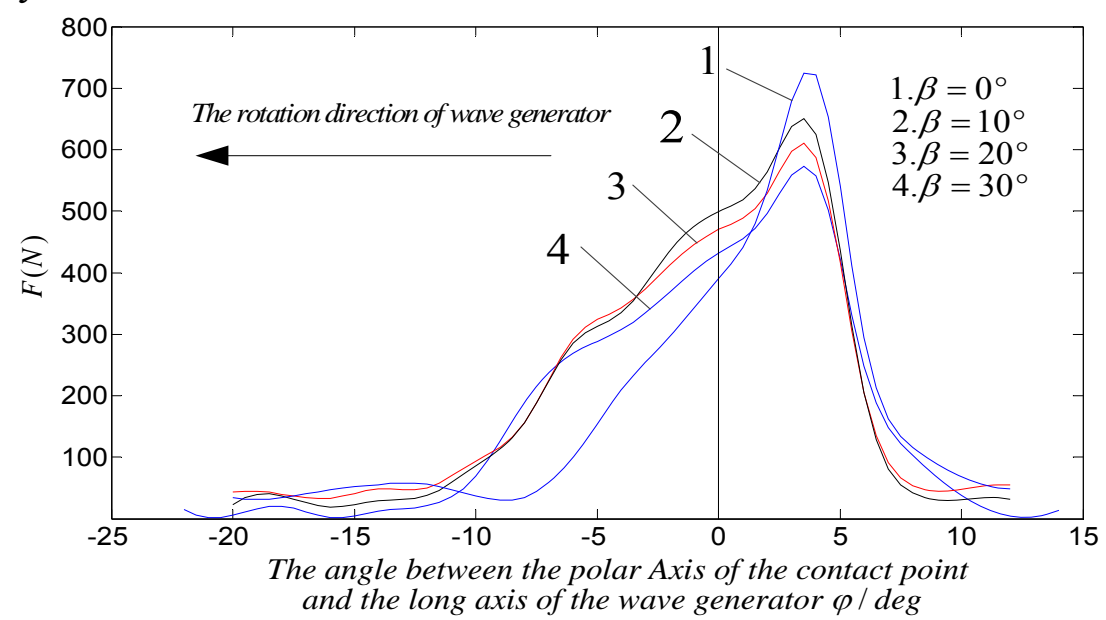

Fig.4 The flexspline load distribution among teeth under different shapes of wave generator

It can be seen from the above figure:

1) The smaller the force intersection angle of wave generator is, the more concentrated the whole load distribution in meshing zoon, and the larger the maximum load acting on the teeth will be;

2) The smaller the force intersection angle of wave generator is, the more obviously flexspline load distribution among gear teeth will deviate to the opposite direction of wave generator rotational direction. That is because the smaller the wave generator radial displacement constraints to the cylinder wall of flexspline is, the bigger distortion of the flexspline.

\section{Conclusions}

The basic tooth profile equation of flexspline with double circular harmonic gear is proposed in this paper, and the equation of circular spline profile-flexspline conjugate tooth profile has been deduced. Load distribution among gear teeth of the flexspline has been calculated under no-load and load conditions. The influence on load distribution among teeth that the shapes of wave generator and load magnitude exert has been discussed.

\section{References}

[1]. Xianzuan Lu, Junkai Shang. Meshing principle of circular arc gear[M]. China Machine Press, 2003.

[2]. Shijiang Zeng, Jiajun Yang, Xuanfu Wang. The harmonic gear drive movement characteristics analysis with double circular arc tooth profile[J]. Journal of South China University of Technology, 2000, 28(1): 12-14.

[3]. Xiaoxia Chen, Shuzhong Lin, Jingzhong Xing. Harmonic gear assembly model based on the deformation of flexible component[J]. Computer Integrated Manufacturing Systems, 2011, 17(2): 338-343.

[4]. Bowen Cui, Yunwen Shen. Study on the load distribution among meshing teeth of harmonic gear drive by finite element method[J]. Journal of Mechanical Transmission, 1997, 21(1): 7-9.

[5]. Yunwen Shen, Qingtai Ye. The theory and design of harmonic gear drive[M]. Beijing: China Machine Press, 1985. 